Current Opinion in Critical Care 13 (2007): 714-719

\title{
The Architecture of Safety: Hospital Design
}

\author{
Authors: \\ Anjali Joseph, PhD \\ Director of Research \\ The Center for Health Design \\ 1850 Gateway Boulevard, Suite 1083 \\ Concord, CA 94520 \\ Tel: 925-521-9404 \\ ajoseph@healthdesign.org
}

Mahbub Rashid, PhD, AIA

Associate Professor of Design

University of Kansas

1467 Jayhawk Boulevard, Suite 300

Lawrence, KS 66045

Tel: 785-864-4405 (Office)

mrashid@ku.edu 


\section{Structured Abstract}

Purpose of review: This article reviews the recent research literature reporting the effects of hospital design on patient safety.

Recent Findings: Features of hospital design that are linked to patient safety in the literature include noise, air quality, lighting condition, patient room design, unit layout, and several other interior design features. Some of these features act as latent conditions for adverse events and impacts safety outcomes directly and indirectly by impacting staff working conditions. Others act as barriers to adverse events by providing hospital staff opportunities for preventing accidents before they occur.

Summary: While the evidence linking hospital design to patient safety is growing, much is left to be done in this area of research. Nevertheless, the evidence reported in the literature may already be sufficient to have a positive impact on hospital design.

Keywords: hospital design, physical environment, architecture, patient safety, adverse events 


\section{Introduction}

A growing body of research shows that hospital design may directly impact safety in hospitals. It may also indirectly impact safety by triggering adverse events that cause harms to patients and staff. Additionally, hospital design may also impact safety in hospitals by working as a barrier to harmful events. This is an emerging field of research, and the effects of hospital design on safety are not always well understood. There is no single database in the field. High quality research articles are also rare, because many confounding variables are present. As a result, this review includes evidence that was not always generated in critical care settings. Nevertheless, all evidence presented here should be relevant to critical care as well.

\section{The role of hospital design in patient safety}

Hospital design refers to the physical environment that includes the indoor environment (e.g., noise, air quality and lighting), the interior design (e.g., furniture, fixtures and materials) and the configuration (e.g., relative locations and adjacencies of spaces) of a hospital. According to the model of system accidents proposed by Reason [1], hospital design may impact patient safety, directly or indirectly, as a latent failure and a barrier.

Reason [1] argues that adverse events in hospitals are related to both active and latent failures. Active failures are unsafe acts (slips, lapses, fumbles, mistakes and procedural violations) committed by the people in direct contact with the patient. In contrast, latent failures create local conditions that in specific situations may lead to active failures. Latent failures may become embedded within systems as a result of wrong decisions made by designers, builders, procedure writers and top level management [2]. As a latent failure, hospital design can directly impact safety outcomes or it can impact staff 
outcomes negatively (e.g. staff stress, fatigue, annoyance, lack of control, lack of motivation, and lack of communication) leading to accidents and errors.

Reason [1] also argues that design barriers may be critical to preventing harmful accidents in hospitals. While a poorly designed and maintained hospital provides the conditions that precipitate accidents, a well designed hospital can have inbuilt safeguards/barriers that may make it difficult for these accidents to occur or that may help stop the chain of events before they result in accidents.

However, hospital design cannot be considered in isolation with regards to patient and staff safety. In almost all safety situations, hospital design interacts with a host of other factors, such as the culture of the organization, tasks and processes in place, and tools and technology. This paper primarily focuses on the role of hospital design while recognizing the contributing role played by other critical factors.

\section{Direct impacts on patient safety}

Aspects of hospital design such as air quality, lighting, patient room design and other interior design elements can directly impact safety outcomes such as nosocomial infections, patient falls and medical errors.

\section{Air quality and nosocomial infections}

Airborne infections are spread when dust and pathogens are released during hospital construction [3-6] and due to contamination and malfunction of hospital ventilation systems [7-10]. Studies in hospitals show that fungal load in the air may be linked to humidity, temperature and construction activity [e.g., $\left.6^{\star}\right]$. High efficiency particulate air filters (HEPA) can be highly effective in preventing airborne infections in hospitals [11]. 
Air contamination is least in laminar airflow rooms with HEPA filters, and this approach is recommended for such areas as operating-room suites and ultraclean-rooms for

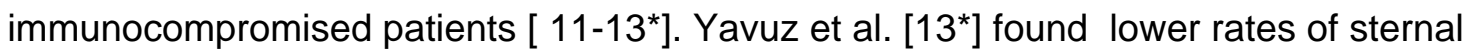
surgical site infections in the newer operating rooms with laminar floor ventilation systems and automatically closing doors as compared to the older operating rooms with standard plenum ventilation and doors that did not close properly.

\section{Single bedrooms and nosocomial infections}

Ulrich et al. [14] identified 16 studies linking the number of patients in a room to nosocomial infection rates. The European Prevalence of Infection Control in Intensive Care study reported an odds ratio for infection of 1.3 in ICUs with more than 11 beds compared to those with fewer than 5 beds. This study, however, did not report any findings related to open versus closed room [15]. Mullin [16] reported a decrease in Acinetobacter baumanii in mechanically ventilated patients, from $28.1 \%$ to $5 \%$, after moving from a unit with both enclosed and open patient-care areas to one with all private rooms.

In general, the reported evidence shows that single-bed patient rooms with high-quality HEPA filters and with negative or positive pressure ventilation are more effective in preventing air-borne pathogens. The evidence also shows that multi-bed rooms are more difficult to decontaminate and have more surfaces that act as a reservoir for pathogens. On the basis of the study findings, the 2006 American Institute of Architects (AIA) Guidelines for Design and Construction of Health Care Facilities has adopted the single bed room as the standard for all new construction in the United States [17]. In addition, several other professional and scientific bodies in the UK, the USA, and Europe have published ICU design guidelines that include similar design measures to control 
nosocomial infections [18].

\section{Lighting conditions and patient outcomes}

A large body of literature reports different psychological and physiological effects of lighting in hospitals, some of which may be directly related to patient safety. For example, "ICU psychosis" in adult patients can be partly attributed to bright and/or constant lighting conditions in ICUs that lack night/day cues. A similar phenomenon has been described among children in PICUs [e.g., 19, 20]. Additionally, mortality rate may be higher in dull patient rooms, with sex having differential effects [21, 22]. Furthermore, poor lighting conditions may negatively impact physiological developments among infants [e.g., 23]. These studies suggest that lighting conditions should be considered more carefully in the design of patient care areas of a hospital.

\section{Lighting conditions and medical errors}

Performance on visual tasks gets better as light levels increase [24]. Buchanan et al. [25] found that errors in dispensing medications in a high volume outpatient pharmacy was significantly lower at an illumination level of 146 foot-candles $(2.6 \%)$ as opposed to the baseline level of 45 foot candles (3.8\%). In Alaska, Roseman \& Booker [26] found that fifty-eight percent of all medication errors among hospital workers occurred during the first quarter of the year when daylight hours were less. Studies in offices indicate the importance of appropriate lighting levels for complex tasks requiring excellent vision [27], but no such study has been reported in hospitals. 
Noise in hospitals and patient outcomes

Noise levels in most hospitals are higher than World Health Organization (WHO) recommendations [28]. The level of noise in the ICU ranges from 50 to $75 \mathrm{~dB}$, with peaks of up to $85 \mathrm{~dB}$ [e.g., 29]. Parthasarathy and Tobin [30] reports that $20 \%$ of all arousals and awakenings among ICU patients are related to noise. They argue that sleep disruption can induce sympathetic activation and elevation of blood pressure, which may contribute to patient morbidity. "ICU psychosis" in adult ICUs and in PICUs has also been partly attributed to a high level of noise in these areas [19, 20]. Common sources of noise in hospitals may include telephones, alarms, trolleys, ice machines, paging systems, nurse shift change, staff caring for other patients, door closing, staff conversations, and patient crying out or coughing [31 ]. Cropp et al. [32] counted 33 different audio signals in a respiratory CCU. Ten were critical alarms requiring immediate nursing action, while the others did not require immediate action and/or were unnecessary. It is clear that patient safety as it relates to hospital noise can easily be improved if proper design and management measures are in place.

\section{Hospital design and patient falls}

A report by the Joint Commission on Accreditation of Healthcare Organization (JCAHO) cites the physical environment as a root cause in $50 \%$ of patient falls [33], but studies show contradictory evidence on the topic. A recent review and meta analysis of randomized controlled trials did not find any evidence for the independent effectiveness of environmental modification programs on patient falls [34*]. Yet, some studies showed that most patient falls occurred in the patient room and that bedrails were the only design element linked strongly with falls $\left[35^{\star *}\right]$. Other studies showed that comprehensive multi-intervention strategies that included environmental modifications 
could be effective in reducing falls [35** $36-38]$.

Among specific interior design elements, flooring can contribute to incidence of falls and the severity of injuries upon impact [39]. Donald [40] reports fewer falls of geriatric patients on vinyl floors as compared to carpeted floors in a rehabilitation ward. However, this study lacks sufficient power. Healy [41], on the other hand, reports that patients suffer more injuries when they fall on vinyl floors versus carpeted floors. Simpson [42] reports that the sub-floors may impact the injury from falls with the risk of fracture being lower for wooden sub-floors as compared to concrete sub-floors.

\section{Impact of the environment on staff working conditions}

A poorly designed physical environment creates latent conditions such as staff stress, fatigue, annoyance, burnout and lack of handwashing compliance that may potentially lead to adverse events in hospitals.

Noise in hospitals and staff outcomes

Studies show that noise is strongly related to stress and annoyance among nurses, and that noise-induced stress is related to emotional exhaustion and burnout among criticalcare nurses $[43,44]$. Healthcare staff reports that the excessively high noise levels at work interfere with their work and impact patient comfort and recovery [45]. Blomkvist and colleagues [46 34] examined the effects of changing the acoustic conditions (using sound absorbing versus sound reflecting ceiling tiles) on the same group of nurses in a coronary intensive-care unit. During the periods of improved acoustic conditions, many positive outcomes were observed among staff including improved speech intelligibility, reduced perceived work demands and perceived pressure and strain [46]. There is 
convincing evidence that noise is a latent condition for errors in hospitals and strategies must be adopted to reduce noise.

\section{Variable acuity patient rooms and transfers}

Patients are transferred from one room to another as often as 3 to 6 times during their short stay in the hospital in order to receive the care that matches their level of acuity $[47,48]$. Delays, communication discontinuities, loss of information and changes in computers and systems during patient transfer may contribute to increased medical errors, loss of staff time and productivity $[48,49]$.

Hendrich and colleagues $[47,48]$ developed an innovative demonstration project called the Cardiac Comprehensive Critical Care (CCCC) at Clarian Methodist Hospital in Indianapolis to address patient transfer and associated errors. The project provided different levels of care in a single patient room to minimize patient transfer as acuity levels changed. For this, each patient room was equipped with an acuity adaptable headwall, and all nurses on the unit were trained to respond to patients with varying acuity levels. The impact of this 56 -bed variable acuity unit on different outcomes was measured by comparing 2 years of baseline data (before the move) and three years of data after the move. They reported significant post-move improvement in many key areas: patient transfers decreased by $90 \%$, medication errors by $70 \%$ and there was also a drastic reduction in the number of falls. This path-breaking project demonstrated the potential impact of acuity adaptable care in dealing with patient flow and safety issues while improving the model of care. Since this project, many hospitals across the country have adopted some variations of the concept though the impacts of these changes on outcomes remain to be studied. 


\section{Unit layout and staff effectiveness}

Nurses spend a lot of time walking - that includes the time to locate and gather supplies and equipment and to find other staff members [50**]. One study found 28.9 percent of nursing staff time was spent walking [51]. This came second only to patient-care activities, which accounted for 56.9 percent of staff time. Unnecessary walking leads to a waste of precious staff time and adds to fatigue and stress among staff.

Studies seem to suggest that bringing staff and supplies physically and visually closer to the patient may help reduce walking $[52,53]$. To take advantage of the idea, many hospitals incorporate decentralized nurses' stations and supplies' servers next to patient rooms (as opposed to locating everything at a single central location). Hendrich and colleagues [48] argue that such a layout may help reduce walking and supply trips. As a result, nursing time may increase significantly allowing for a reduction in budgeted staffing care hours while increasing time spent in direct patient care activities. An indepth discussion on how various aspects of unit design, patient room design and staff areas may contribute to staff effectiveness is provided in the review of best practice examples of adult intensive care units designed between 1993 and 2003 by Rashid $\left[54^{* *}\right]$.

\section{Accessibility to handwashing stations and handwashing compliance}

Surface transmission of pathogens accounts for a majority of nosocomial infections and low handwashing frequency among healthcare staff (generally below $50 \%$ ) is a key factor contributing to this problem [55]. Design factors that discourage handwashing include: difficulty of access, poor visibility, poor height placement, lack of redundancy, and wide spatial separation of resources that are used sequentially while washing hands [55-58]. 
Studies report conflicting evidence on the effects of physical design on handwashing compliance. Some studies found that handwashing compliance was higher in units with higher sink to bed ratios $[59,60]$. One study found no significant improvement in handwashing after a move from an open ward design to a layout with single patient rooms and higher sink to bed ratios [61]. Trick and colleagues [62*] found that hand hygiene improved during the study period in 3 intervention hospitals (where interventions included increased availability of alcohol based hand rubs, an interactive education program and a poster campaign) but not at the control hospital (where the only intervention was increased availability of alcohol hand rubs). These and other studies seem to suggest that a multi-strategy intervention that includes staff education as well as easy visual and physical access to sinks, standard locations of sinks in all patient rooms, comfortable sink heights and alcohol-based dispensers may be more effective in increasing handwashing compliance $[55,58]$.

\section{Environmental barriers/defenses to healthcare accidents}

The environment potentially acts as a defense to adverse events by providing opportunities for staff and families to prevent accidents before they occur.

\section{Visibility to patients}

One important way to avert adverse events related to patients is for the staff to have the ability to observe patients continuously and provide assistance as needed. Multiple decentralized nurse work areas and charting alcoves next to patient rooms may help facilitate this activity. Such designs enable the staff to attend patient's needs without delays. In at least one prospective study, Hendrich et al. [63] showed that falls were cut 
by $2 / 3$ - from six-per-thousand patients to two-per-thousand-after a move from an old unit with centralized nursing station to a new unit with decentralized observation units. Additional research is needed to learn the effects of decentralization on patient safety.

Visibility to patients seems to be related to perceived safety as well. In a staff survey by France et al. [64] at a new NICU and PCCU at a children's hospital (designed with single patient rooms, curtains for privacy for families, larger unit size, but with poor sightlines between staff and patients), a majority of the respondents believed that the facility design made team communication and patient monitoring difficult and that it limited social interaction among staff. Thus, while making major facility changes it is critical to take into consideration patient needs for privacy as well as staff needs for monitoring and communication.

\section{Presence of family}

Another effective way to avert adverse events is to allow the patient's family to be a part of the patient care process. In order to understand how teamwork and communication involving the patient's family may contribute to patient safety, Dr. Paul Uhlig and colleagues conducted multidisciplinary collaborative rounds at the patient bedside in 1999 in a cardiac surgery program in Concord, New Hampshire [65]. These rounds involved the patient's family as well. The team participated in 10-minute briefings at the patient's bedside at the start of the day, and reviewed the patient's care plan, discussed medication and addressed anything that went wrong in an open, blame-free environment [64 53]. Following these changes, patient mortality rates declined significantly [66].

In order to include families as active participants in the care process it is important to provide spaces for families in the patient room and on the unit where they can spend 
extended periods of time. Single rooms have clear advantage over multi-bed rooms in this regard due to increased privacy $\left[14,67^{\star \star}\right]$. A survey of nurses in four hospitals found that nurses gave high ratings to single rooms for accommodating family members but accorded double rooms low scores $\left[67^{\star *}\right]$. In addition to these factors, organizational policies such as those that limit family visitation hours may influence family involvement and satisfaction with care.

\section{Conclusions}

Hospital design may help improve patient safety directly by reducing nosocomial infections, patient falls, medication errors and, sometimes, even by reducing patient morbidity and mortality. Hospital design may also help improve patient safety indirectly by reducing staff stress, staff walking and patient transfer, and by improving handwashing compliance. In contrast, very little has been reported recently on the role of hospital design as a barrier to adverse events in hospitals. While research on the links between hospital design and safety has grown over the last few years, there is still a need for more focused studies. Some reported contradictions on these links also need to be resolved. Meanwhile, the growing body of evidence in the field may already have an impact on how hospitals should be designed in the coming years. 


\section{References and Recommended Reading}

Papers of particular interest, published within the period of this review have been highlighted as:
* Of special interest
** Of outstanding interest

[1] Reason J. Human error: Models and management. British Medical Journal. 2000;320:768-70.

[2] Vincent C, Taylor-Adams S, Stanhope N. Framework for analysing risk and safety in clinical medicine. British Medical Journal. 1998;316(11 April):1154-7.

[3] Opal SM, Asp AA, Cannady PB, et al. Efficacy of infection control measures during a nosocomial outbreak of disseminated aspergillosis associated with hospital construction. Journal of Infectious Diseases. 1986;153(3):634-7.

[4] Oren I, Haddad N, Finkelstein R, Rowe J M. Invasive pulmonary aspergillosis in neutropenic patients during hospital construction: Before and after chemoprophylaxis and institution of HEPA filters. American Journal of Hematology. 2001;66(4):257-62.

[5] Humphreys $\mathrm{H}$, Johnson EM, Warnock DW, et al. An outbreak of aspergillosis in a general ITU. The Journal of Hospital Infection. 1991 Jul;18(3):167-77.

[6] Panagopoulou P, Filioti J, Farmaki E, et al. Filamentous fungi in a tertiary care hospital: Environmental surveillance and susceptibility to antifungal drugs. Infection Control and Hospital Epidemiology. 2007;28(1):60-7.

${ }^{*}$ An environmental sampling study for air and surface fungal loads in a hospital in Greece over a 12-month period. 
[7] Kumari DN, Haji TC, Keer V, et al. Ventilation grilles as a potential source of methicillin-resistant Staphylococcus aureus causing an outbreak in an orthopaedic ward at a district general hospital. The Journal of Hospital Infection. 1998;39(2):127-33.

[8] Lutz BD, Jin J, Rinaldi MG, et al. Outbreak of invasive Aspergillus infection in surgical patients, associated with a contaminated air-handling system. Clinical Infectious Diseases. 2003;37(6):786-93.

[9] McDonald LC, Walker M, Carson L, et al. Outbreak of Acinetobacter spp. bloodstream infections in a nursery associated with contaminated aerosols and air conditioners. The Pediatric Infectious Disease Journal. 1998 Aug;17(8):716-22.

[10] Clark T, Huhn GD, Conover C, et al. Outbreak of Bloodstream Infection With the Mold Phialemonium Among Patients Receiving Dialysis at a Hemodialysis Unit Infection Control and Hospital Epidemiology. 2006;27(11):1164-70.

[11] Hahn T, Cummings KM, Michalek AM, et al. Efficacy of high-efficiency particulate air filtration in preventing aspergillosis in immunocompromised patients with hematologic malignancies. Infection control and hospital epidemiology. 2002;23(9):525-31.

[12] Friberg S, Ardnor B, Lundholm R. The addition of a mobile ultra-clean exponential laminar airflow screen to conventional operating room ventilation reduces bacterial contamination to operating box levels. The Journal of Hospital Infection. 2003 Oct;55(2):92-7.

[13] Yavuz SS, Bicer Y, Yapici N, et al. Analysis of risk factors for sternal surgical site infection: Emphasizing the appropriate ventilation of the operating theaters Infection Control and Hospital Epidemiology. 2006;27(9):958-63.

${ }^{\star}$ A prospective cohort study examining risk factors for sternal surgical site infections.

[14] Ulrich RS, Zimring C, Joseph A, et al. The role of the physical environment in the hospital of the 21st century: A once-in-a-lifetime opportunity. Concord, CA: The Center for Health Design; 2004. 
[15] Vincent JL, Bihara DJ, Suter PM, et al. The prevalence of nosocomial infection in intensive care units in Europe: Results of the European Prevalence of Infection in Intensive Care (EPIC) Study. JAMA. 1995;274:639-644.

[16] Mullin B, Rouget C, Clement C, et al. Association of private rooms with ventilator associated Acinetobacter Baumanii pneumonia in a surgical intensive-care unit. Infect Control Hosp Epidemiol 1997;18:499-503.

[17] Facilities Guidelines Institute. Guidelines for Design and Construction of Health Care Facilities. Washington, DC: The American Institute of Architects; 2006.

[18] O'Connell NH, Humphreys $\mathrm{H}$. Intensive care unit design and environmental factors in the acquisition of infection. Journal of Hospital Infection. 2000;45:255-262.

[19] Gelling L. Causes of ICU psychosis: the environmental factors. Nurs Crit Care. 1999;4:22-6.

[20] Hughes J. Hallucinations following cardiac surgery in a pediatric intensive care unit. Intensive Crit Care. 1994;10:209-11.

[21] Beauchemin KM, Hays P. Sunny Hospital Rooms Expedite Recovery from Severe and Refractory Depressions. Journal of Affective Disorders. 1996;40(1-2):49-51. [22] Beauchemin KM, Hays P. Dying in fhe Dark: Sunshine, Gender and Outcomes in Myocardial Infarction. Journal of the Royal Society of Medicine. 1998;91:352-354. [23] Brandon DH, Holditch-Davis D, Belyea M. . Preterm Infants Born at Less Than 3 Weeks' Gestation Have Improved Growth in Cycled Light Compared With Continuous Near Darkness. Journal of Pediatrics. 2002;140:192-199.

[24] Boyce P, Hunter C, Howlett O. The benefits of daylight through windows. Troy, New York: Rensselaer Polytechnic Institute; 2003 September 12.

[25] Buchanan TL, Barker KN, Gibson JT, Jiang BC, Pearson RE. Illumination and errors in dispensing. American Journal of Hospital Pharmacy. 1991 Oct;48(10):2137-45. 
[26] Roseman C, Booker JM. A seasonal pattern of hospital medication errors in Alaska. Psychiatry Research. 1995; 57(3):251-257.

[27] Rashid M, Zimring C. A review of the empirical literature on the relationships between indoor environment and stress in healthcare and office settings: Problems and prospects of sharing evidence - A Technical Report. Lawrence, KS: University of Kansas; 2007.

[28] Busch-Vishniac I, West J, Barnhill C, et al. Noise levels in John Hopkins Hospital. Journal of the Acoustical Society of America. 2005 December;118(6):3629-45.

[29] Gabor JY, Cooper AB, Crombach SA, et al. Contribution of the intensive care unit environment to sleep disruption in mechanically ventilated patients and healthy subjects. Am J Respir Crit Care Med. 2003;167:708-715

[30] Parthasarathy S, Tobin MJ. Sleep in the intensive care unit. Intensive Care Medicine. 2004;30:197-206.

[31] Ulrich RS, Lawson B, \& Martinez M. Exploring the patient environment: An NHS estates workshop. London: The Stationery Office; 2003.

[32] Cropp A, Woods L, Raney D, Bredle D. Name that tone: the proliferation of alarms in the intensive care unit. Chest. 1994;105:1217-1220.

[33] Joint Commission on Accreditation of Healthcare Organizations. Root causes of patient falls. Sentinel event statistics [Graph] 2006 [cited 2007 7/22/07]; Available from: http://www.jointcommission.org/NR/rdonlyres/FA5A080F-C259-47CC-AAC8BAC3F5C37D84/0/se_rc_patient_falls.jpg

[34] Oliver D, Connelly JB, Victor CR, Shaw FE. Strategies to prevent falls and fractures in hospitals and care homes and effect of cognitive impairment: Systematic review and meta-analyses. British Medical Journal. 2007;334(7584):82.

${ }^{*}$ A strong meta analysis of factors related to inpatient falls. 
[35] Hignett S, Masud T. A review of environmental hazards associated with in-patient falls. Ergonomics. 2006;5-6:605-16.

** The paper provides a good discussion of environmental hazards related to fall and puts forth an environmental hazards assessment model for conducting assessments.

[36] Alcee DA. The experience of a community hospital in quantifying and reducing patient falls. Journal of Nursing Care Quality. 2000 Apr;14( 3):43-54.

[37] Becker C, Kron M, Lindemann U, et al. Effectiveness of a multifaceted intervention on falls in nursing home residents. Journal of the American Geriatrics Society. 2003 Mar;51(3):306-13.

[38] Brandis S. A collaborative occupational therapy and nursing approach to falls prevention in hospital inpatients. Journal of Quality in Clinical Practice. 1999;19(4):21521.

[39] Drahota A, Gal D, Windsor J. Flooring as an intervention to reduce injuries from falls in healthcare settings. Quality in Ageing. 2007;8(1):3-9.

${ }^{*}$ An interesting review of the impact of flooring type and characteristics on injuries from falls, includes new product assessments.

[40] Donald IP, Pitt K, Armstrong E, Shuttleworth H. Preventing falls on an elderly care rehabilitation ward. Clinical Rehabilitation. 2000 Apr;14(2):178-85.

[41] Healey F. Does flooring type affect risk of injury in older in-patients? Nursing Times. 1994;90(27):40-1.

[42] Simpson AHRW, Lamb S, Roberts PJ, et al. Does the type of flooring affect the risk of hip fracture? Age and Ageing. 2004;33(3):242-6.

[43] Topf M, Dillon E. Noise-induced stress as a predictor of burnout in critical care nurses. Heart Lung. 1988 Sep;17(5):567-74.

[44] Morrison WE, Haas EC, Shaffner DH, et al. Noise, stress, and annoyance in a pediatric intensive care unit. Critical Care Medicine. 2003 Jan;31(1):113-9. 
[45] Bayo MV, Garcia AM, Garcia A. Noise levels in an urban hospital and workers' subjective responses. Archives of Environmental Health. 1995 May-Jun;50(3):247-51.

[46] Blomkvist V, Eriksen CA, Theorell T, et al. Acoustics and psychosocial environment in coronary intensive care. Occupational and Environmental Medicine. 2005;62:1-8.

[47] Hendrich A, Lee N. Intra-unit patient transports: Time, motion, and cost impact on hospital efficiency. Nursing Economic\$. 2005;23(4):157-64.

[48] Hendrich A, Fay J, Sorrells A. Effects of acuity-adaptable rooms on flow of patients and delivery of care. American Journal of Critical Care. 2004 January;13(1):3545.

[49] Cook RI, Render M, Woods DD. Gaps in the continuity of care and progress on patient safety. British Medical Journal. 2000 Mar 18;320(7237):791-4.

[50] Tucker A, Spear S. Operational failures and interruptions in hospital nursing. Health Services Research. 2006 June;41(3):643-62.

${ }^{* *}$ Through surveys, interviews and observations at 48 nursing units, this interesting study reveals that nurses are interrupted very frequently while performing critical tasks.

[51] Burgio L, Engel B, Hawkins A, et al. A descriptive analysis of nursing staff behaviors in a teaching nursing home: Differences among NAs, LPNs and RNs. The Gerontologist. 1990;30:107-12.

[52] Shepley MM, Davies K. Nursing unit configuration and its relationship to noise and nurse walking behavior: An AIDS/HIV unit case study. AIA Academy Journal [Electronic journal] 2003 [cited 2004 5/26/2004]; Available from: http://www.aia.org/aah/journal/0401/article4.asp

[53] Shepley MM. Predesign and postoccupancy analysis of staff behavior in a neonatal intensive care unit. Children's Health Care. 2002;31(3):237-53. 
[54] Rashid M. A decade of adult intensive care unit design: A study of physical design features of best-practice examples. Critical Care Nursing Quarterly. 2006;29(4):282-311.

${ }^{* *}$ This paper provides an excellent review of issues related to designing critical care units based on literature review and review of best practice examples.

[55] Joseph A. The Impact of the Environment on Infections in Healthcare Facilities. Concord, CA: The Center for Health Design; 2006 July

[56] Larson E, Albrecht S, O’Keefe M. Hand hygiene behavior in a pediatric emergency department and a pediatric intensive care unit: Comparison of use of 2 dispenser systems. American Journal of Critical Care. 2005 July;14(4):304-11.

[57] Lankford MG, Zembower TR, Trick WE, et al. Influence of role models and hospital design on hand hygiene of healthcare workers. Emergency Infectious Diseases. 2003 Feb;9(2):217-23.

[58] Boyce J. Antiseptic technology: Access, affordability, and acceptance. Emerging Infectious Diseases. 2001 March-April;7(2):231-33.

[59] Kaplan LM, McGuckin M. Increasing handwashing compliance with more accessible sinks. Infection Control. 1986 Aug;7(8):408-10.

[60] Vernon MO, Trick WE, Welbel SF, et al. Adherence with hand hygiene: Does number of sinks matter? Infection control and hospital epidemiology. 2003 $\operatorname{Mar} ; 24(3): 224-5$

[61] Vietri NJ, Dooley DP, Davis CE, et al. The effect of moving to a new hospital facility on the prevalence of methicillin-resistant Staphylococcus aureus. American Journal of Infection Control. 2004;32(5):262-7.

[62] Trick W, Vernon M, Welbe IS, Demarais $\mathrm{P}$, et al. Multicenter intervention program to increase adherence to hand hygiene recommendations and glove use and to reduce 
the incidence of antimicrobial resistance. Infection Control and Hospital Epidemiology. 2007;28(1):42-9.

* This prospective observational study examines the impact of installing alcohol-based hand rubs and education programs on staff handwashing compliance.

[63] Hendrich A. Case Study: The impact of Acuity Adaptable rooms on future designs, bottlenecks and hospital capacity. Impact Conference on optimizing the physical space for improved outcomes, satisfaction and the bottom line; 2003; Atlanta, GA: The Institute for Healthcare Improvement \& The Center for Health Design; 2003.

[64] France D, Throop P, Walczyk B, et al. Does patient-centered design guarantee patient safety?: Using human factors engineering to find a balance between provider and patient needs. Journal of Patient Safety. 2005 September;1(3).

[65] McCarthy D, Blumenthal D. Committed to safety: Ten case studies on reducing harm to patients. New York, NY: Commonwealth Fund; 2006. Report No.: 923.

[66] Uhlig P. Reconfiguring clinical teamwork for safety and effectiveness. Focus on Patient Safety. Indianapolis: National Patient Safety Foundation 2002:1-2.

[67] Chaudhury H, Mahmood A, Valente M. Nurses' perception of single-occupancy versus multioccupancy rooms in acute care environments: An exploratory comparative assessment. Applied Nursing Research. 2006;19:118-25.

${ }^{* *}$ This paper provides an excellent discussion of the literature on benefits of designing single patient rooms along with findings from a pilot survey of nurses. 